\title{
COLLISION SYSTEM OF WEST PRIBAIKALIE: AEROSPACE GEOLOGICAL MAP OF OLKHON REGION (BAIKAL, RUSSIA)
}

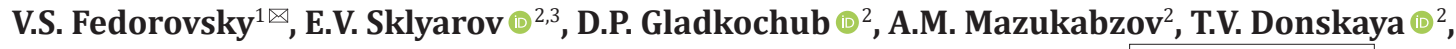 A.V. Lavrenchuk ${ }^{4,5}$, A.E. Starikova ${ }^{4,5}$, N.L. Dobretsov ${ }^{6}$, A.B. Kotov ${ }^{(7}{ }^{7}$, Ark.V. Tevelev ${ }^{8}$}

\footnotetext{
${ }^{1}$ Geological Institute, Russian Academy of Sciences, 7 Pyzhevsky Ln, Moscow 119017, Russia

${ }^{2}$ Institute of the Earth's Crust, Siberian Branch of the Russian Academy of Sciences, 128 Lermontov St, Irkutsk 664033, Russia

${ }^{3}$ Far Eastern Federal University, 10 Ajax Bay, Russky Island, Vladivostok 690922, Russia

${ }^{4}$ Sobolev Institute of Geology and Mineralogy, Siberian Branch of the Russian Academy of Sciences, 3 Academician Koptyug Ave, Novosibirsk 630090, Russia

${ }^{5}$ Novosibirsk State University, 2 Pirogov St, Novosibirsk 630090, Russia

${ }^{6}$ Trofimuk Institute of Petroleum Geology and Geophysics, Siberian Branch of the Russian Academy of Sciences, 3 Academician Koptyug Ave, Novosibirsk, Russia

${ }^{7}$ Institute of Precambrian Geology and Geochronology, Russian Academy of Sciences, 2 Makarov Emb, Saint Petersburg 199034, Russia

${ }^{8}$ Lomonosov Moscow State University, 1 Leninskie Gory, Moscow 119991, Russia
}

ABSTRACT. We announce the second edition of the Aerospace geological map of the Olkhon Region (Baikal, Russia), scale 1:40000, which was published in 2017. The map has been considerably revised and updated, and its changes are critical for correct understanding of the regional geology, tectonics and geodynamics. Only a small number of its printed copies have been released, and therefore the map may not be available for all interested specialists. The electronic version of the map is available for studying and/or printing (see the link to its pdf file in the paper's supplement). The pdf file is about $68 \mathrm{MB}$, i.e. small compared to the original map (more than $5 \mathrm{~GB}$ ), but the quality is maintained. The map does not show the base layer due to the terms of the licenses owned by the companies and satellite owners.

KEY WORDS: Aerospace geological map; Olkhon region

FUNDING: Financial support for the research - RFBR grants 08-05-00177, 11-05-00267, 12-05-00229, 13-05-00557, 14-05-00231, 16-05-00202, 17-05-00203, and 20-05-00005; and grant of the Government of the Russian Federation № 075-15-2019-1883.

\section{SHORT COMMUNICATION}

Correspondence: Valentin S. Fedorovsky, valentinfedorovskii@mail.ru

FOR CITATION: Fedorovsky V.S., Sklyarov E.V., Gladkochub D.P., Mazukabzov A.M., Donskaya T.V., Lavrenchuk A.V., Starikova A.E., Dobretsov N.L., Kotov A.B., Tevelev Ark.V., 2020. Collision system of West Pribaikalie: Aerospace geological map of Olkhon region (Baikal, Russia). Geodynamics \& Tectonophysics 11 (3), 447-452. doi:10.5800/GT-2020-11-3-0485

Supplementary files: Aerospace geological map_Olkhon region_Baikal_Russia.pdf 


\title{
КОЛЛИЗИОННАЯ СИСТЕМА ЗАПАДНОГО ПРИБАЙКАЛЬЯ: АЭРОКОСМИЧЕСКАЯ ГЕОЛОГИЧЕСКАЯ КАРТА ОЛЬХОНСКОГО РЕГИОНА (БАЙКАЛ, РОССИЯ)
}

\section{В.С. Федоровский ${ }^{1}$, Е.В. Скляров ${ }^{2,3}$, Д.П. Гладкочуб ${ }^{2}$, А.М. Мазукабзов ${ }^{2}$, Т.В. Донская ${ }^{2}$, А.В. Лавренчук ${ }^{4,5}$, А.Е. Старикова ${ }^{4,5}$, Н.Л. Добрецов ${ }^{6}$, А.Б. Котов ${ }^{7}$, Арк.В. Тевелев ${ }^{8}$}

\author{
${ }^{1}$ Геологический институт РАН, 119017, Москва, Пыжевский пер., 7, Россия \\ ${ }^{2}$ Институт земной коры СО РАН, 664033, Иркутск, ул. Лермонтова, 128, Россия \\ ${ }^{3}$ Дальневосточный федеральный университет, 690922, Владивосток, о. Русский, п. Аякс, 10, Россия \\ ${ }^{4}$ Институт геологии и минералогии им. В.С. Соболева СО РАН, 630090, Новосибирск, пр-т ак. Коптюга, 3, Россия \\ ${ }^{5}$ Новосибирский государственный университет, 630090, Новосибирск, ул. Пирогова, 2, Россия \\ ${ }^{6}$ Институт нефтегазовой геологии и геофизики им. А.А. Трофимука СО РАН, 630090, Новосибирск, пр-т ак. \\ Коптюга, 3, Россия \\ ${ }^{7}$ Институт геологии и геохронологии докембрия РАН, 199034, Санкт-Петербург, наб. Макарова, 2, Россия \\ ${ }^{8}$ Московский государственный университет им. М.В. Ломоносова, 119991, Москва, Ленинские горы, 1, Россия
}

АНнотАЦИЯ. Настоящее краткое сообщение является в значительной степени анонсом второго издания Аэрокосмической геологической карты Ольхонского региона (Байкал, Россия) м-ба 1:40000, изданной в 2017 г. Изменения по сравнению с первым изданием карты весьма значительны и принципиально важны для понимания геологии, тектоники и геодинамики региона. Карта отпечатана небольшим тиражом, поэтому вряд ли будет доступна всем заинтересованным специалистам. В статье же приводится ссылка на электронный вариант карты (pdf-файл), размещенный в дополнительных материалах к статье на сайте журнала, который можно изучать или распечатывать для пользования. Размер электронного варианта файла карты (около 68 Мб) невелик по сравнению с оригиналом (более 5 Гб), однако потери качества нет, из него только удален базовый слой по условиям лицензий, полученных от компаний и владельцев спутников.

КЛЮЧЕВЫЕ СЛОВА: Аэрокосмическая геологическая карта; Ольхонский регион

ФИНАНСИРОВАНИЕ: Финансовая поддержка исследований - РФФИ (гранты 08-05-00177, 11-05-00267, 1205-00229, 13-05-00557, 14-05-00231, 16-05-00202, 17-05-00203, 20-05-00005), грант Правительства Российской Федерации № 075-15-2019-1883.

В 2010 г. в журнале «Геодинамика и тектонофизика» была опубликована статья «Ольхонский геодинамический полигон (Байкал): аэрокосмические данные высокого разрешения и геологические карты нового поколения» [Fedorovsky, Sklyarov, 2010]. На примере этой территории (рис. 1) авторы пытались, с одной стороны, показать высокий потенциал использования в геологии данных дистанционного зондирования Земли, а с другой - обсудить перспективы иной, чем прежде, интерпретации массива новых геологических данных, накопленных к тому времени и кардинально изменивших представления о геологии и тектонике Западного Прибайкалья. Одним из итогов многолетней работы, которая предшествовала той публикации, стало составление и издание Аэрокосмической геологической карты Тажеранского массива нового поколения масштаба 1:10000 [Fedorovsky et al., 2009], первой из серии детальных карт ключевых площадей Ольхонского геодинамического полигона. Позднее были составлены и изданы карты северо-востока Приольхонья, Черноруда, Тонты, Крестовской пади, Анга-Бегула и юго-запада острова Ольхон [Fedorovsky et al., 2011, 2012, 2013; Sklyarov et al., 2012, 2013]. В статье анонсировалась и идея издания геологической карты, которая охватывала бы всю территорию Приольхонья и о-ва Ольхон.

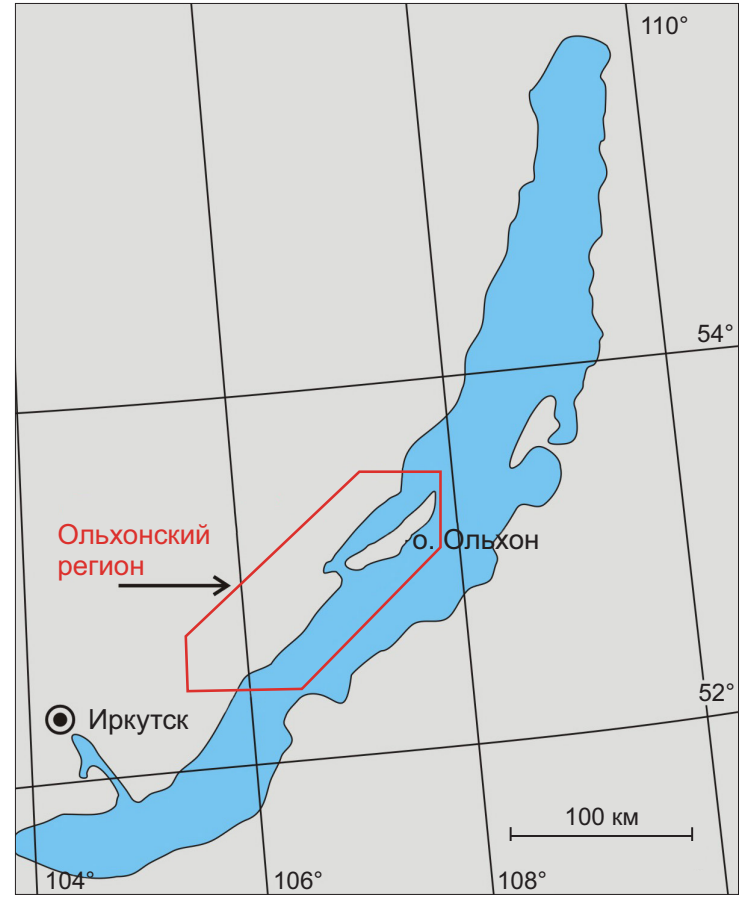

Рис. 1. Схема расположения Ольхонского региона Западного Прибайкалья.

Fig. 1. Schematic map of the Olkhon region, West Pribaikalie. 
Тогда казалось, еще год-два и такая карта будет составлена. Эта работа действительно быстро продвигалась, однако непрерывно поступающий новый полевой геологический и аналитический материал заставлял вносить коррективы, касающиеся нередко и базовых представлений. Стало ясно, что спешка здесь неуместна. Было очевидно, однако, и другое - без геологической карты, которая отражала бы реальный образ коллизионной системы, вскрытой здесь в современном срезе, дальнейшее продвижение в исследованиях вряд ли возможно.

В 2017 г. такая Аэрокосмическая геологическая карта практически всего Ольхонского региона была составлена и издана [Fedorovsky et al., 2017]. И вместе с тем авторы статьи хотели бы подчеркнуть, что было бы неверно рассматривать эту карту как окончательный итог наших знаний о геологическом строении данной территории Западного Прибайкалья. Работа продолжается, и, как и раньше, новые полевые и аналитические данные поступают непрерывно. Нередко они (это неизбежно) снова и снова приводят к необходимости очередных корректив, а иногда и серьезных изменений концептуального характера. И такая ситуация оказывается перманентной. Карта только что издана. И она уже устарела... Между тем Ольхонский регион занимает ключевую позицию в системе основных структур Азии: здесь проходит граница между Сибирским кратоном и Центрально-Азиатским поясом. Выяснить историю их взаимодействия во времени и пространстве интересная и актуальная задача.

Издание бумажного варианта карты - «удовольствие» дорогое, поэтому мы предлагаем читателю нестандартный вариант - публикацию новой электронной аэрокосмической геологической карты Ольхонского региона в журнале «Геодинамика и тектонофизика» (см. вкладку Дополнительные материалы на странице статьи), с возможностью опубликования очередного издания карты при появлении принципиальных отличий от опубликованных версий. Изменения по сравнению с первым изданием карты [Fedorovsky et al., 2017] весьма значительны и принципиально важны для понимания геологии, тектоники и геодинамики региона. Сильно сжатый вариант карты показан на рис. 2.

В данной публикации нет никаких пояснительных текстов, только сама геологическая карта и ее легенда (на русском и английском языках). Это сделано специально. Мы планируем публикацию серии статей, освещающих различные аспекты геологии, тектоники и геодинамики коллизионной системы Западного Прибайкалья. Они будут опираться на материал, использованный при составлении геологической карты, опубликованной в данной статье.

В зарамочном поле карты размещены схемы различного содержания (тектоники, геодинамики, метаморфизма, зон синтаксисов, цифрового 3D-рельефа по данным радарной космической съемки, схема использованных данных дистанционного аэрокосмического зондирования, а также аэрофотоснимки сверхкрупного масштаба и космические снимки сверхвысокого пространственного разрешения на ряд опорных площадей территории).

Аэрокосмический дистанционный материал, использованный в полевой работе и при составлении карты, весьма обширен (рис. 3). Он включает панхроматические и мультиспектральные космические снимки с десяти спутников США, Франции и Японии (в том числе данные сверхвысокого пространственного разрешения, т.е. крупнее 1:5000), а также данные аэрофотосъемки четырех масштабов (все - Россия), в том числе сверхкрупного (1:5000).

Территория региона характеризуется высокой степенью обнаженности (в скалах прибрежной зоны Байкала и проливов она достигает 100 \%). Высок и потенциал дешифрирования дистанционных данных. К примеру, панхроматические космические снимки со спутников GeoEye-1, WORLD VIEW-2, QUICK BIRD-2, IKONOS-2 имеют сверхвысокое пространственное разрешение $(41,46,61$, 80 cм/пиксель), отвечающее масштабам 1:1500 - 1:5000. На них видны такие детали геологического строения, которые обеспечивают уверенность при распознавании границ геологических тел и точность при их нанесении на карты, которая прежде была недостижима.

Нужно отметить и высокое качество отечественных аэрофотоматериалов не только крупного масштаба (1:5000 и 1:12000, специальная аэрофотосъемка), но и стандартной аэрофотосъемки масштаба 1:25000. На таких изображениях уверенно дешифрируются крупные структуры.

Космический материал по региону, которым мы располагаем, обрабатывался в программном комплексе ENVI (компания ITT Visual Information Solutions, ныне Exelis Visual Information Solutions, Inc., США). В полевой работе использованы и радарные космические 3-секундные цифровые 3D-модели рельефа, генерированные нами в программе GLOBAL MAPPER из базы данных миссии SRTM (The Shuttle Radar Topography Mission, спутник SHUTTLE, США, пространственное разрешение 90 м). На полевых маршрутных картах - в участках с хорошей степенью обнаженности - ошибка в нанесении геологических границ не превышала 1-5 м.

Интегрированная цифровая геологическая карта содержит в базовом слое в качестве «топоосновы» мозаику из космических снимков со спутников WORLD VIEW-2, IKONOS-2, QUICK BIRD-2. Все они приведены к единому масштабу (1:5000) и попиксельно привязаны к глобальной трехмерной системе координат World Geodetic System 1984 (WGS 84). «Пустые» площади, не охваченные космической съемкой (их немного), закрыты аэрофотоснимками сверхкрупного масштаба (1:5000, Россия). Они не оцифрованы, но приведены к масштабу космических снимков и по контрольным точкам совмещены нами вручную. Подчеркнем, что, упоминая слово «топооснова», мы не подразумеваем под этим привычные топографические карты. Хотя такие карты любого масштаба у нас есть, пользоваться ими достаточно бессмысленно, поскольку по сравнению с той информацией, 


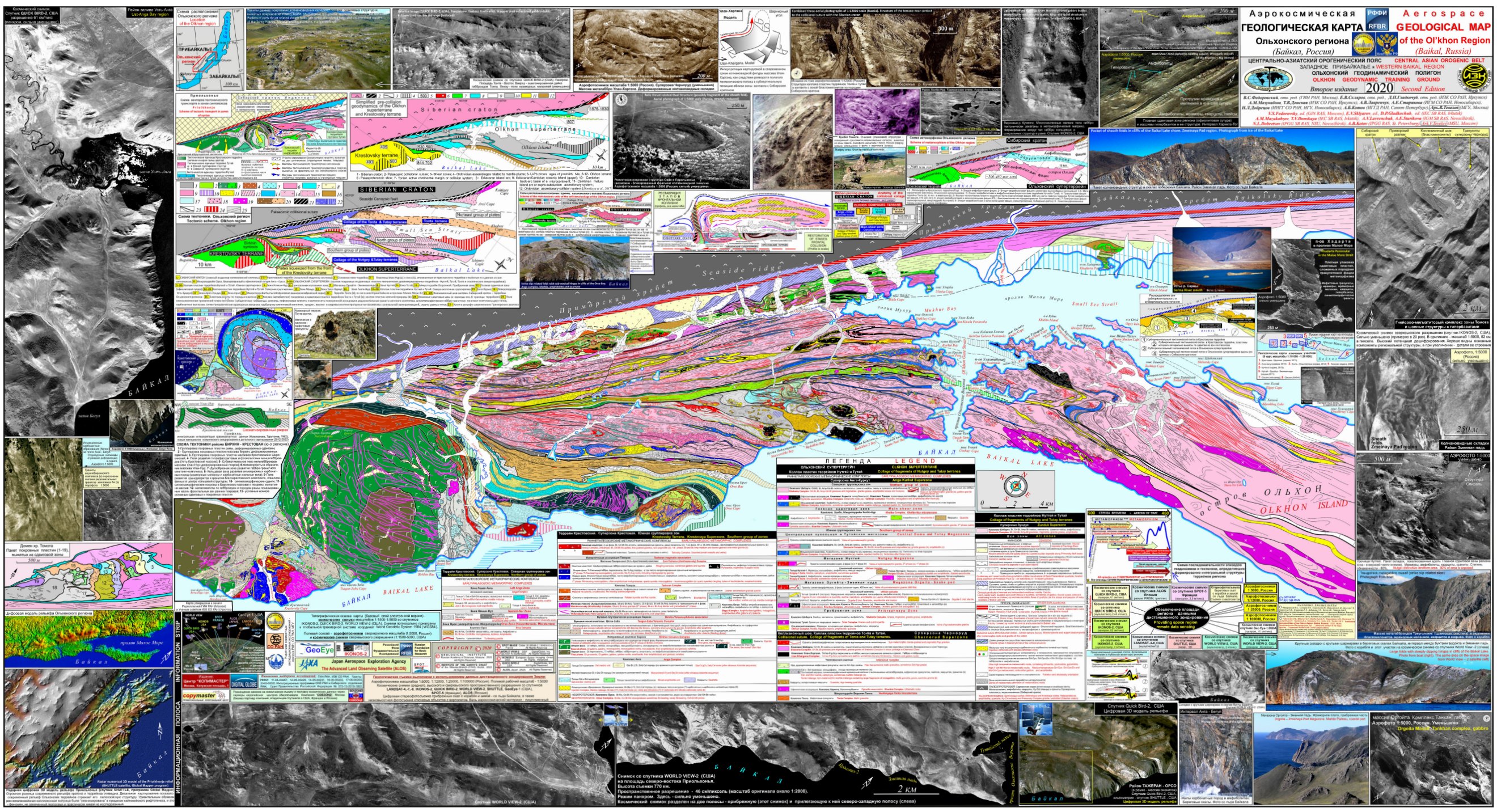

Рис. 2. Аэрокосмическая геологическая карта Ольхонского региона (Байкал, Россия). Второе издание, 2020 (сильно сжатый вариант).

Fig. 2. Aerospace geological map of the Olkhon region (Baikal, Russia). Second edition, 2020 (strongly zoomed-out). 


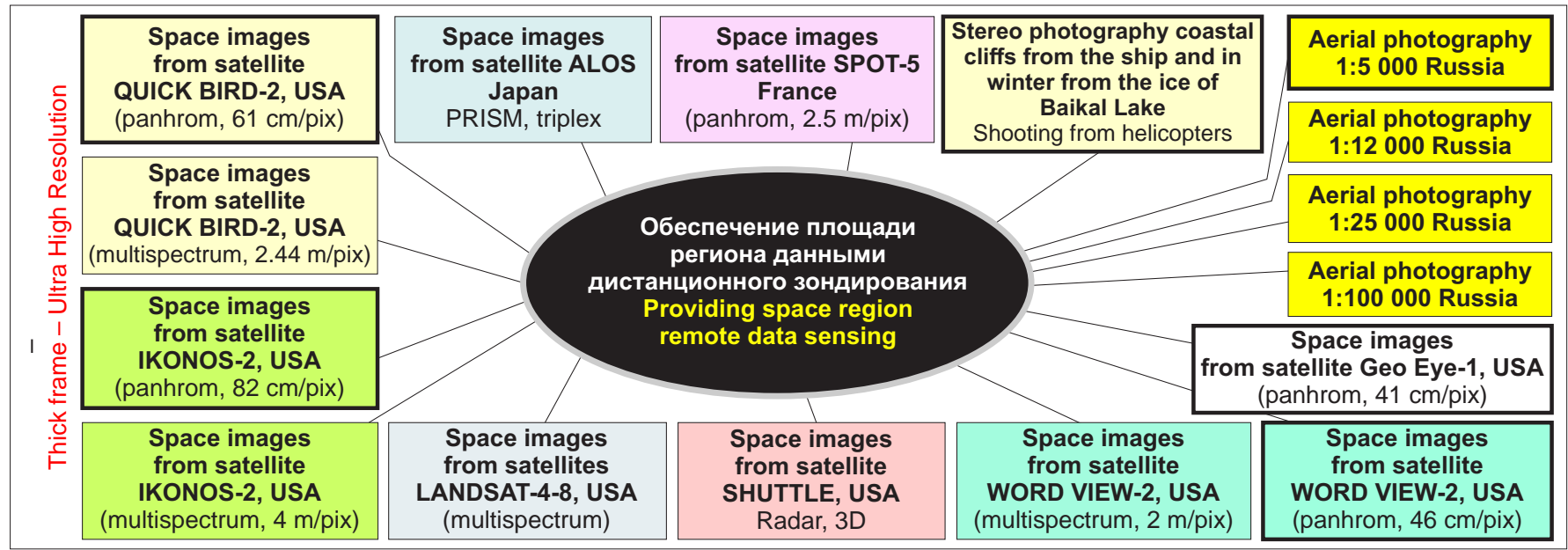

Рис. 3. Обеспечение площади Ольхонского региона Западного Прибайкалья данными дистанционного зондирования Земли (по состоянию на 2020 г.). Толстая рамка - материал сверхвысокого пространственного разрешения (1:5000 и крупнее).

Fig. 3. Coverage of the Olkhon region (West Pribaikalie) with remote sensing data (as of 2020). Thick frame - ultra-high spatial resolution $(1: 5000+)$.

которая присутствует на космических снимках, топокарты проигрывают им по любым параметрам. Это в полном смысле слова - прошлый век. Да и карт нужной нам детальности просто не существует. Ведь рабочий масштаб космических и аэрофотоснимков, которые мы используем в геологических маршрутах, 1:5000 и крупнее. Топокарт такого класса на площадь Ольхонского полигона нет. Они практически и не нужны.

«Размер» оригинала электронной карты (геология плюс базовый слой с космическими снимками и аэрофотоснимками) составляет примерно 5 гигабайт. В изданной карте (в том числе в ее электронном варианте) базовый слой удален. Таковы условия лицензий, полученных от компаний, владельцев спутников. Размер файла изданной карты невелик - 250 мегабайт. В данной статье использован один из ее растровых вариантов (65-150 мегабайт). Понятно, что такие упражнения с файлом бесследно не проходят, однако геологические контуры и тексты легенды видны все же достаточно четко.

\section{БЛАГОДАРНОСТИ И КОПИРАЙТЫ}

Кроме авторов в совместных полевых маршрутах в разные годы участвовали геологи из институтов Российской академии наук, расположенных в Москве, Иркутске, Санкт-Петербурге, Новосибирске (С.П. Кориковский, Г.С. Закариадзе, С.А. Силантьев, А.Б. Лихачев, Г.В. Риле, С.Ф. Карпенко, Л.Ф. Добржинецкая, Т.В. Молчанова, О.А. Астраханцев, К.А. Докукина, И.К. Кацура, Ю.Ф. Соколова, С.Н. Чамов, В.В. Ким, А.Г. Владимиров, В.И. Сухоруков, С.В. Хромых, С.А. Каргополов, М.Л. Куйбида, В.И. Левицкий). В плодотворных и напряженных дискуссиях во время полевых экскурсий участвовали А. Крёнер, К. Пассье (Германия), Б. Уиндли (Великобритания), Р. Хэтчер (США), Дж. Шенгер (Турция), а также многие геологи из Китая, Монголии, Тайваня, Южной Кореи. Мы признательны всем коллегам.
В полевой работе учтены геологические карты различных частей региона, составленные ранее в разных масштабах в ИФЗ РАН (г. Москва) и ИЗК СО РАН (г. Иркутск).

Аэрокосмическая геологическая карта Ольхонского региона защищена копирайтом. Правообладатели: ГИН РАН (г. Москва) и ИЗК СО РАН (г. Иркутск). Все права сохранены (C).

Полевые исследования выполнены в рамках научных программ ГИН РАН (г. Москва), ИЗК СО РАН (г. Иркутск), ИГМ СО РАН (г. Новосибирск), ИГГД РАН (г. С.-Петербург), МГУ (г. Москва) и интеграционных программ ОНЗ РАН и Сибирского отделения РАН.

Лицензионный космический материал приобретен при финансовой поддержке ГИН РАН (г. Москва), ИЗК СО РАН (г. Иркутск), РФФИ (несколько грантов), программы «Электронная Земля» Президиума РАН. Космический материал защищен копирайтами. Все права сохранены. Копирование запрещено (C).

Снимки со спутников WORLD VIEW-2, QUICK BIRD2, IKONOS-2. GeoEye-1 (все - США), SPOT-5(Франция), ALOS (Япония) закуплены из архивов компаний - владельцев спутников. Космическая съемка Ольхонского региона со спутника QUICK BIRD-2 (США) выполнена по заказу ГИН РАН в рамках акции, проведенной оператором Digital Globe. Снимки со спутников LANDSAT-4, -7, -8 и радарного спутника SHUTTLE (все - CША) получены в открытом доступе через Интернет.

Размещение заказов и оперативную поставку космических данных через серверы европейских центров обеспечивала компания «СОВЗОНД» (г. Москва), официальный дистрибьютор ведущих операторов спутников дистанционного зондирования Земли и бизнеспартнер компаний - владельцев спутников в США, Франции и Японии (http://www.sovzond.ru). Благодарим Н.П. Дейниченко, директора СОВЗОНДа по работе с ключевыми заказчиками. Ее советы и содействие 
вдохновляли нас в поисках лучших дистанционных данных в море архивного космического материала, а также при заказе новой космической съемки, выполненной на площадь Ольхонского региона аппаратом QUICK BIRD-2.

C горечью вспоминаем ушедших из жизни друзей и соратников по совместным полевым экспедициям в Прибайкалье, выдающихся геологов - чл.-корр. РАН Сергея Кориковского (ИГЕМ РАН) и профессора МГУ Аркадия Тевелева.

\section{ЛИТЕРАТУРА / REFERENCES}

Fedorovsky V.S., Mazukabzov A.M., Sklyarov E.V., Gladkochub D.P., Donskaya T.V., Lavrenchuk A.V., Agatova A.R., Kotov A.B., 2012. Aerospace Geological Map South-West Part of Chernorud and Tomota Zone of Olkhon Region (Lake Baikal). A1TIS Group, Moscow.

Fedorovsky V.S., Mazukabzov A.M., Sklyarov E.V., Gladkochub D.P., Donskaya T.V., Lavrenchuk A.V., Kotov A.B., 2013. Aerospace Geological Map of the North-Eastern Part of Zones Chernorud and Tomota, Priolkhoniye (Lake Baikal). Copymaster Center, Moscow.

Fedorovsky V.S., Sklyarov E.V., 2010. The Olkhon Geodynamic Proving Ground (Lake Baikal): High-Resolution Satellite Data and Geological Maps of New Generation. Geodynamics \& Tectonophysics 1 (4), 331-418 (in Russian) [Федоровский В.С., Скляров Е.В. Ольхонский геодинамический полигон (Байкал): Аэрокосмические данные высокого разрешения и геологические карты нового поколения//
Геодинамика и тектонофизика. 2010. Т. 1. № 4. С. 331418]. https://doi.org/10.5800/GT-2010-1-4-0026.

Fedorovsky V.S., Sklyarov E.V., Gladkochub D.P., Mazukabzov A.M., Donskaya T.V., Lavrenchuk A.V., Starikova A.E., Dobretsov N.L., Kotov A.B., Tevelev Ark.V., 2017. Aerospace Geological Map of the Olkhon Region (Baikal, Russia). Copymaster Center, Moscow.

Fedorovsky V.S., Sklyarov E.V., Mazukabzov A.M., Gladkochub D.P., Donskaya T.V., Lavrenchuk A.V., Izokh A.E., Agatova A.R., Kotov A.B., 2011. Geological Map of the North-Eastern Part of Priolkhoniye (Baikal). Zone Nutgey and Orgoyta Snake Pad'. A1TIS Group, Moscow.

Fedorovsky V.S., Sklyarov E.V., Mazukabzov A.M., Kotov A.B., Kargopolov S.A., Lavrenchuk A.V., Starikova A.E., 2009. Geological Map of the Tazheran Massif (Baikal). Scale 1:100000. A1TIS Group, Moscow, 2009 (in Russian) [Федоровский В.С., Скляров Е.В., Мазукабзов А.М., Котов А.Б., Каргополов С.А., Лавренчук А.В., Старикова А.Е. Геологическая карта массива Тажеран (Байкал). Масштаб 1:100000. М.: Группа компаний A1 TIS, 2009].

Sklyarov E.V., Fedorovsky V.S., Lavrenchuk A.V., Starikova A.E., Kotov A.B., Mazukabzov A.M., 2013. Aerospace Geological Map of Anga - Begul Interfluve (Baikal). The Right Anga Zone. Copymaster Center, Moscow.

Sklyarov E.V., Fedorovsky V.S., Mazukabzov A.M., Gladkochub D.P., Donskaya T.V., Lavrenchuk A.V., Starikova A.E., Agatova A.R., Kotov A.B., 2012. Aerospace Geological Map of South-West Part of the Olkhon Region (Lake Baikal). Krestovsky - Shirokaya Zone. A1TIS Group, Moscow. 